\title{
ELECTROCHROMIC NICKEL OXIDES THIN FILMS DEPOSITED ON ITO : AN ELECTROCHEMICAL AND ELECTRON MICROSCOPY STUDY
}

\author{
Dwight R. Acosta, Carlos R. Magaña, Luis Rendón \\ Instituto de Física, UNAM, A.P. 20-364; 01000 México D.F.; MÉXICO \\ dacosta@fisica.unam.mx
}

The electrochromic materials receive particular attention due to the great variety of practical applications in energy conservation [1,2,] and in semitransparent optical devices [4]. Typical of electrochromic materials is a reversible and persistent change of their optical properties when are under the influence of an external electrical field. Nickel and nickel oxide films were deposited by magnetron sputtering on transparent and conducting film; the ITO thin films used as substrates were previously deposited on glass substrates by spray pyrolysis (SP) and DC magnetron sputtering (MS) respectively. The electrochromism phenomena was induced during cyclic voltammetry processes; the cyclic potential range was set from an initial potencial of $-400 \mathrm{mV}$ to an ending potential of 600 $\mathrm{mV}$; the scan rate used runned from 400 to $600 \mathrm{mV} / \mathrm{min}$. The working area of the sample was $2 \mathrm{~cm}^{2}$.

The electrochromic phenomena in our samples was detected in cyclic voltammograms close to 100 cycles; the changes of coloration in the deposited films is clearly observed in both types of deposits. The cyclic voltammograms of electrochromic nickel-ITO prepared by spray pyrolysis and sputtering indicate differences in the behavior of the same materials for each scanning speeds. The electrochromic phenomena induced during voltammetry experiments, is due to the mobility, diffusion and insertion of ions from the electrolyte into the nickel thin film structure. This interactions suggested changes in the arrangement of the original stucture to the modificated one and this has to do with variation in the coloration of nickel oxide films; this change can be originated upon hydrogen extraction and it is associated with phase changes in nickel oxide compounds $[5,6]$.

In figures $1 \mathrm{a}$ and $1 \mathrm{~b}$ cyclic voltagrams for samples with ITO deposited by spray pyrolysis and magnetron sputtering respectively are presented for scanning speed $400 \mathrm{mV} / \mathrm{min}$ and $600 \mathrm{mV} / \mathrm{min}$ for each case. Two principal peaks in each cycle, corresponding to the oxidation and reduction processes during the electrochemical experiment. It can be observd when both figures are studied at the same time the peaks positions are displaced when the scanning speed and the number of cycles are changed.

In figures $2 \mathrm{a}$ and $2 \mathrm{~b}$ SEM micrographs of Ni-ITO thin films before and after electrochemical treatment are presented, for ITO obtained for spray pyrolysis and nickel by sputtering. The changes in the surface of the films after and before the electrochromic materials can be asociated in the electrochemical voltagrams when this values in the formation of the species increase in each cycle, having diferents density and size in the grains on the surface of the nickel thin film.

From HREM micrographs in figures $3 \mathrm{a}$ and $3 \mathrm{~b}$ we can corroborate at atomic scale, the modifications in the surface of the films caused when the electrochromic behavior in our materials is induced. The thin films under an external voltage in the electrolytic cell, experiment a degradation process as consequence of ion mobility, mass transpot and intercalation phenomena. 

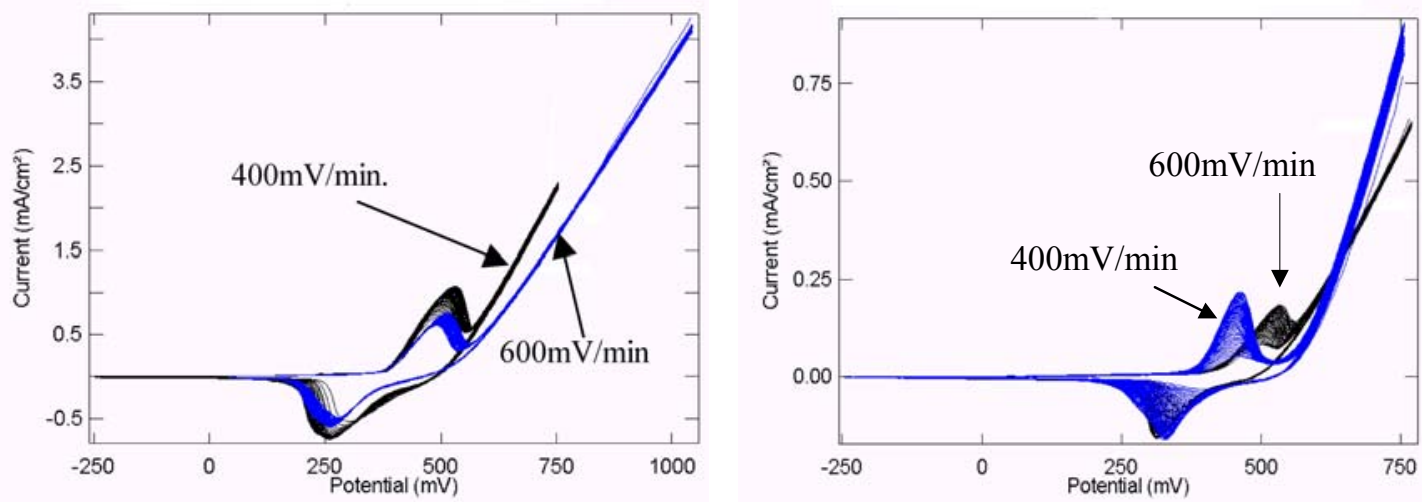

Figures 1.- Cyclic voltammograms of electrochromic nickel-ITO prepared by (a) spray pyrolysis and (b) sputtering respectively for two differents scannng speeds.
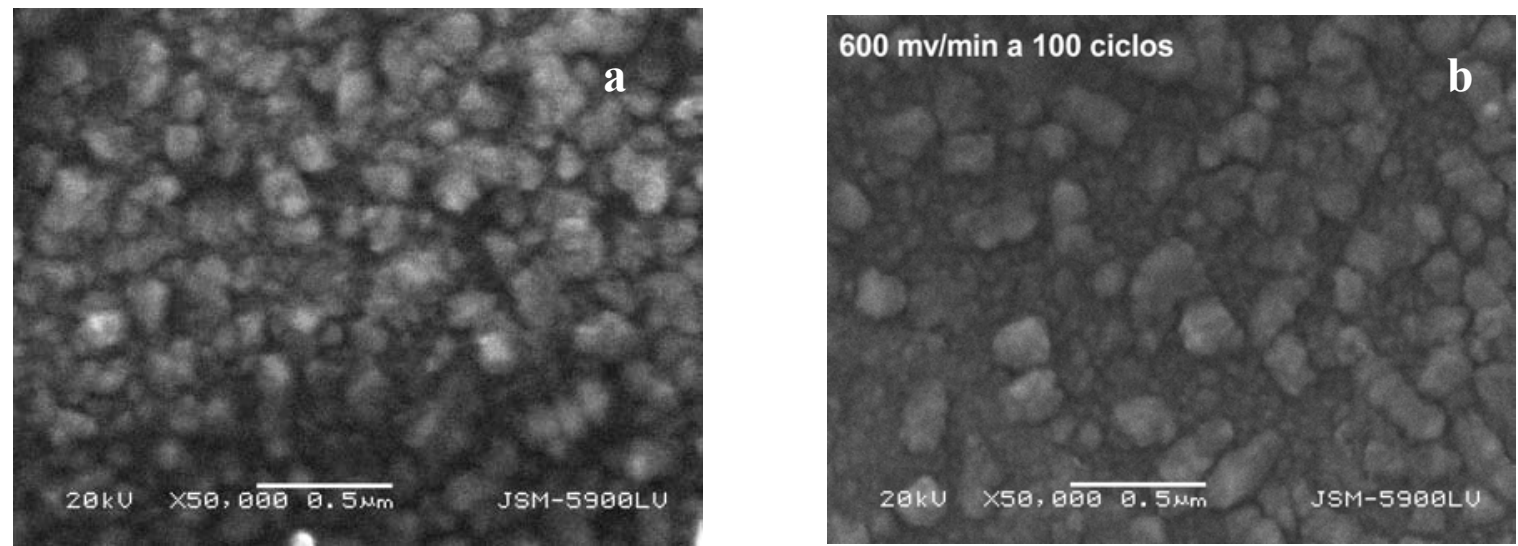

Figure 2and 2b- SEM micrograph of the surface of as-deposited Ni-ITO thin film by spray pyrolysis without electrochemical treatment, b) Thin film surface after applied 100 cycles (electrochemical treatment) at $600 \mathrm{mV} / \mathrm{min}$ scanning speed.
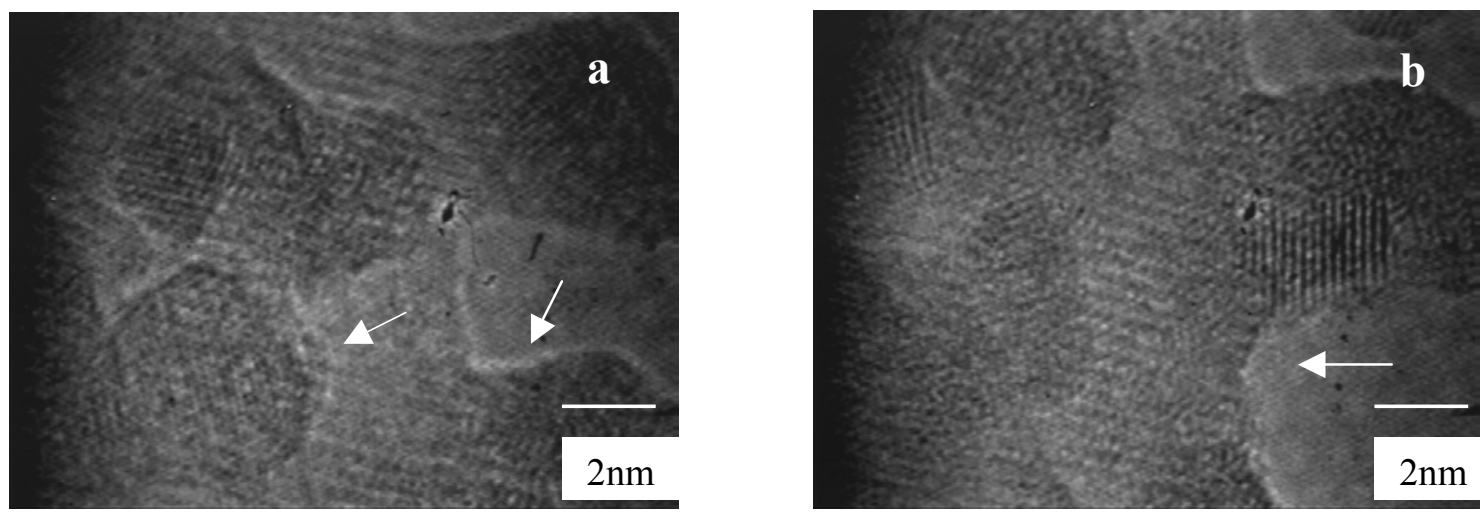

Figures $3 \mathrm{a}$ and 3b.- HREM micrograph of Ni-ITO (Sputtering) film after 100 cycles of cyclic voltammetry and with a scanning speed of $600 \mathrm{mV} / \mathrm{min}$, the arrows show the degradation zones.

\section{REFERENCES}

1. C.G. Granqvist, Handbook of inorganic electrochromic materials. 1995 Elsevier

2. F.G. Baucke Mat. Sci. and Eng. B10(1991) 285-292.

3. I.Hotovy, J.HuranSensors and Actuators, B 57(1999) 147-152

4. J.S.E.M. Svensson and C.G. Granqvist. Appl. Phys Lett. 49 (23), 1986 pp1566-1568

5. Y. Ushio, A. Ishikawa, T. Niwa.Thin Solid Film 280 (1996) 233-237.

6. X. Chen, X. Hu, J. Feng. NanoStructured Materials, Vol 6, pp309-312, 1995. 